\title{
The Neighborhood-School Characteristics: As an Effective Factor of Social Sustainability in Neighborhood
}

\author{
Parisa Ziaesaeidi ${ }^{1}$ \\ ${ }^{1}$ Department of Architecture, Yazd University, Iran \\ Correspondence: Parisa Ziaesaeidi, Department of Architecture, Yazd University, Iran. \\ E-mail:prszsd@gmail.com
}

Received: November 17, 2017

Accepted: January 22, 2018

Online Published: March 30, 2018

doi:10.5539/jsd.v11n2p34

URL: https://doi.org/10.5539/jsd.v11n2p34

\begin{abstract}
The neighborhood unit promotes quality of life, community feeling, and well-being by providing facilities. Sharing the main facilities of the neighborhood with all residents can play an important role in the satisfaction of the neighborhood. When a school (as one of the facilities) is placed into the neighborhood context, it can affect environmental and social issues. Therefore, the neighborhood facilities and services would not purely increase all residents' satisfaction, well-being and quality of neighborhood through its equal accessibility for all residents. This paper discusses how the quality of the neighborhood can be enhanced and promoted by the different characteristics of facilities like schools.

The research method is based on an analysis of the affective features of a primary school on social sustainability in the neighborhood. The research has been done by recording sample participants' ideas. The questionnaires were administered to 285 participants from two neighborhoods (with neighborhood-school and non-neighborhood-school) in Kerman, Iran. Results confirm that important features of the neighborhood -school have a direct affect on the quality of the neighborhood. The comfort, safety and harmony were identified as the most important of the six presented factors.
\end{abstract}

Keywords: neighborhood-school, sustainable neighborhood, social sustainability, school characteristics, quality of neighborhood

\section{Introduction}

Social sustainability is a quality of being in a place (e.g. neighborhood) and is generally associated with the environment, the perception of the environment, psychological comfort, the ability to establish social relationships, and functional readability at place that creates opportunity for informal encounters and social cohesion (Dempsey, 2008a; Dempsey et al., 2008; Suminski et al., 2006; Bramely et al., 2009; Burton \& Mithell, 2006; Coleman, 1988; Partridge, 2005; Littig \& Griebler, 2005; Dave, 2011; Chan \& Lee, 2007). Most attention to social sustainability is generally given to urban social issues. However, some social sustainability aspects are in relation to satisfaction in the smaller scale -e.g. neighborhoods through built environments (Mitchell \& Burton, 2006; Dempsey, 2009; Dave, 2011; Chan \& Lee, 2007; Karuppannan \& Sivam, 2011).

The built environment as a physical unit in the neighborhood (e.g., school) affects the quality of the local area. This suggests that the study of the neighborhood needs to focus on increasing residents' satisfaction through improving physical environments. There is a need to assess the quality of services and facilities such as schools, public transport services and open spaces in a neighborhood (Dempsey, 2009, p. 340). Thus, there is a prime reason for not dismissing the neighborhood-school (primary school level) as a conceptual tool for a socially sustainable neighborhood. The aim is to understand which characteristics of the neighborhood-school are more effective through social and physical issues, to address all residents' satisfaction with being in the neighborhood. The result of this study will transform feedback into feed forward to show that a school can enhance the quality of a neighborhood.

The paper first discusses the role of school as a neighborhood facility for promoting social sustainability. The second part of paper presents the methods and acquired conceptual framework through residents'opinions. Ultimately, it presents the relationship between quality of neighborhood and social sustainability by enhancing the understanding of neighborhood-school role in socially sustainable neighborhoods. 


\section{Theoretical Background}

\subsection{The Neighborhood and Social Sustainability Context}

The neighborhood concept was developed by Perry (1927) to orient residential development for family life, with other social and community facilities. The neighborhood unit is designed as a physical tool for providing opportunities for residents to interact and expand their sense of place (Lawhon, 2009). So, the developed neighborhood is represented by physically defined units such as a primary school, shops, parks and green spaces, within walking distance of about 15-minutes (Perry, 1927; Stein, 1928; Morris \& Hess, 1975; Barton et al., 2003). The neighborhood may be defined in terms of different aspects. For instance, the neighborhoods are defined functionally by local services contexts; socially by perception of local residents; environmentally by traffic specifications, quality and security and ultimately aesthetically by specified characteristics. A socially sustainable neighborhood includes elements that should have meanwhile continuous and close communications with each other. These elements are as follows (Rogerf, 1999; Dave, 2011; Dempsey, 2008):

- The density of residential development

- The layout of building units and blocks

- Community spirit and social interaction

- $\quad$ Sense of safety

- The hierarchy of open space and the size and distribution of public open spaces, both green and paved

- The mix of land uses

- Integrated transport systems; neighborhood streets, the local distributors, access roads

- $\quad$ Provide good local facilities; shops, primary school, community facilities

Urban management in neighborhood includes an organization consisted of effective and relative formal and informal elements in social, economic and physical dimensions of neighborhood life with the purpose of administrating, controlling and leading the sustainable development of neighborhood for residents' satisfaction (Wheeler, 2004).

Therefore, the requirement of children and residents to travel out of a neighborhood (average distance to nearest daily use) for primary school and other facilities is not a good idea. Resident mobility can be a reason for dissatisfaction and the failure of a neighborhood. This can be exacerbated by a decreasing feeling of attachment by residents moving out of areas (Bramley \& Power, 2009).

The opportunities for social interaction and identity creation of a neighborhood are derived from interaction among residents by placing the community facilities at the center of the neighborhood. These facilities of the neighborhood are fundamental in forming social opportunities for social interaction (Lawhon, 2009). Social interaction in local facilities can be measured by elements such as frequency of meeting neighbors, knowing neighbors, making new friends, feeling strongly attached to the residents and feeling at home (Harnik, 2003; Bramley et al., 2009), stopping to chat with neighbors, and saying hello or participating in collective civic activities (Suminski et al., 2006). The gathering places affect the quality of resident life through reducing the hours of resident mobility outside of the neighborhood. The primary school provides an outlet for residents to engage in social and physical activities (Lawhan, 2009) and it provides a sense of community. This is one of the important reasons for placing the school at the center of the neighborhood.

Indeed, neighborhood facilities as collective places provide the context for residents gathering through frequent participation in community activities. This participation is described as dimensions of social sustainability like social capital (Forrest \& Kearns, 2001), social cohesion and social network integration (Littig \& Griessler, 2005) and is related to the quality of facilities and services in the neighborhood. Residents' attachment and well-being would be enhanced by high-quality of neighborhood environment. It means high- quality of local facilities (include visual aesthetics, the use and perception of space, and the design of sustainable communities) have a positive effect on social activities and behaviors in neighborhood (Dave, 2011) due to their enjoyment of being in neighborhood.

The neighborhood unit supports the urban environment by establishing physical standards that encourage interaction, reducing the effect of the automobile on the safety of residents through less mobility out of neighborhood for daily use and primary school. The perceived safety of a neighborhood is a fundamental part of social sustainability (Barton, 2000a). Therefore, the location of the school enhances the satisfaction with the neighborhood. Satisfaction is associated with social capital and social cohesion, social interaction, social behavior, 
sense of place, pride and attachment, safety and security and sense of comfort and level of interest (Coleman, 1988; Bramley \& Power, 2009).

Finally, based on the literature it can be ascertained that social sustainability can encompass cultural, economic, and social issues, and quality of life in a neighborhood setting. In addition, some of the social sustainability aspects have the relationship between satisfaction in the neighborhood and the built environment such as aesthetics and forms of buildings, density, pathways, scale of buildings and spaces between buildings. In Table1, some of the aspects of social sustainability relating to everyday life to which residents and users need equitable access, have been indicated. Some of these aspects are directly linked to the built environment.

Table 1. Classification of aspects of social sustainability and indicators of social sustainability

\begin{tabular}{lcc}
\hline $\begin{array}{c}\text { Aspects of Social } \\
\text { Sustainability }\end{array}$ & List of Indicators & Determined by \\
\hline
\end{tabular}

Social equity Attachment to the neighborhood; Social interaction; Safety; Knowing the neighborhood; Access to services and opportunities

Social cohesion Opportunities for formal and informal social gathering; Equal access to services and welfare benefits; Sense of morality and common purpose and codes of behavior

Social capital

Open space; Social networks and the associated norms of reciprocity; Participation in local and community activities

Sense of attachment Satisfaction with the neighborhood; Image of neighborhood; Quality of life; Neighborhood as a place to live in; Perceived neighborhood in terms of attractiveness; Architectural character; Well-maintained buildings; Outdoors ; Parking facilities, Quality of environment; Cleanliness; General appearance; Feeling the strongly attached to the neighborhood

Social inclusion Interaction between personal and environment; Belong to the social network; Amenities in the neighborhood and attitudes of neighbors

Sense of safety

Community spirit and Social interaction family members; Security against crimes

Perceived number of social contacts (knowing people) within the neighborhood; Perceived number of informal chats with neighbors
Pincetl, 2003; Partridge, 2005; Bramley, 2009; Power, 2009; Teriman, 2010; Dave ,2011

Coleman, 1988; Bramley, 2009; Dave, 2011; Forrest \& Kearns ,2011

Coleman, 1988; Putnam, 2000; Bramley, 2009; Power, 2009

Relf, 1976; Harnik, 2003; Suminski et al., 2006; Dempsey, 2009; Brown, 2009; Power, 2009; Bramley, 2009; Dave, 2011

Partridge, 2005; Bramley, 2009; Power, 2009; Cobigo, 2012

Burton, 2000a; Worpole, 2003; Mitchell, 2006 reporting of health of resident in terms of number of
Forrest \& Kearns, 2001; Harnik, 2003; Dave, 2011; Karuppannan \& Sivam, 2011

(Source: Author, 2016)

\subsection{The Neighborhood Quality and Neighborhood-School Characteristics}

The neighborhood facilities not only provide a context for social sustainability but also can affect neighborhood satisfaction through the perceived good-quality of the neighborhood through physical features of facilities. So, there is a need to investigate in detail the effect of the neighborhood-school on the quality of neighborhood and neighborhood-school users' satisfaction.

There is much research which implies the environment provides possibilities for behavior and offers a choice to participate therein. Therefore, understanding how the built environment might determine behavior is an important issue (Lawhon, 2009). The neighborhood has been designed according to some desired patterns by the designer 
and urban planner (i.e., the design effect on residents behavior through Physical determinism) who designs for human use and the provision of good-quality places where people feel safe, comfortable, and engaged. Thus, it is necessary to define features of quality of the built environment as a part of the neighborhood. These are features of quality related to the aesthetics, and social dimensions of the built environment (Dempsey, 2008a).

The neighborhood-school as social and physical unit of the neighborhood affects the residents' satisfaction through its features. Indeed, the common thought of a neighborhood-school is the use of it as a built environment for improving the local environment, reducing traffic and making walking more pleasant, enhancing health, aesthetics and enjoyment (Barton et al., 1995, 2003), providing comfort, safety, and increased social and political capital of participants and the local community. So, the main role of the school in the neighborhood is to delineate the local boundaries and provide comfort, safety, and a sense of attachment to that area.

The neighborhood has a physical environment where, by design, layout promotes neighborhood identity through an adequate physical design for schools, parks, community centers, and shopping (Lawhon, 2009). Residents can interact and have cohesive behavior through these features and physical design.

To further define correspondence between social sustainability and aspects of neighborhood-school the Issue-based framework and Goal-based framework have been used (McLaren, 1996; Trraga, 2006; Masnavi, 2007). This framework helps to reveal data gaps (Figure1).

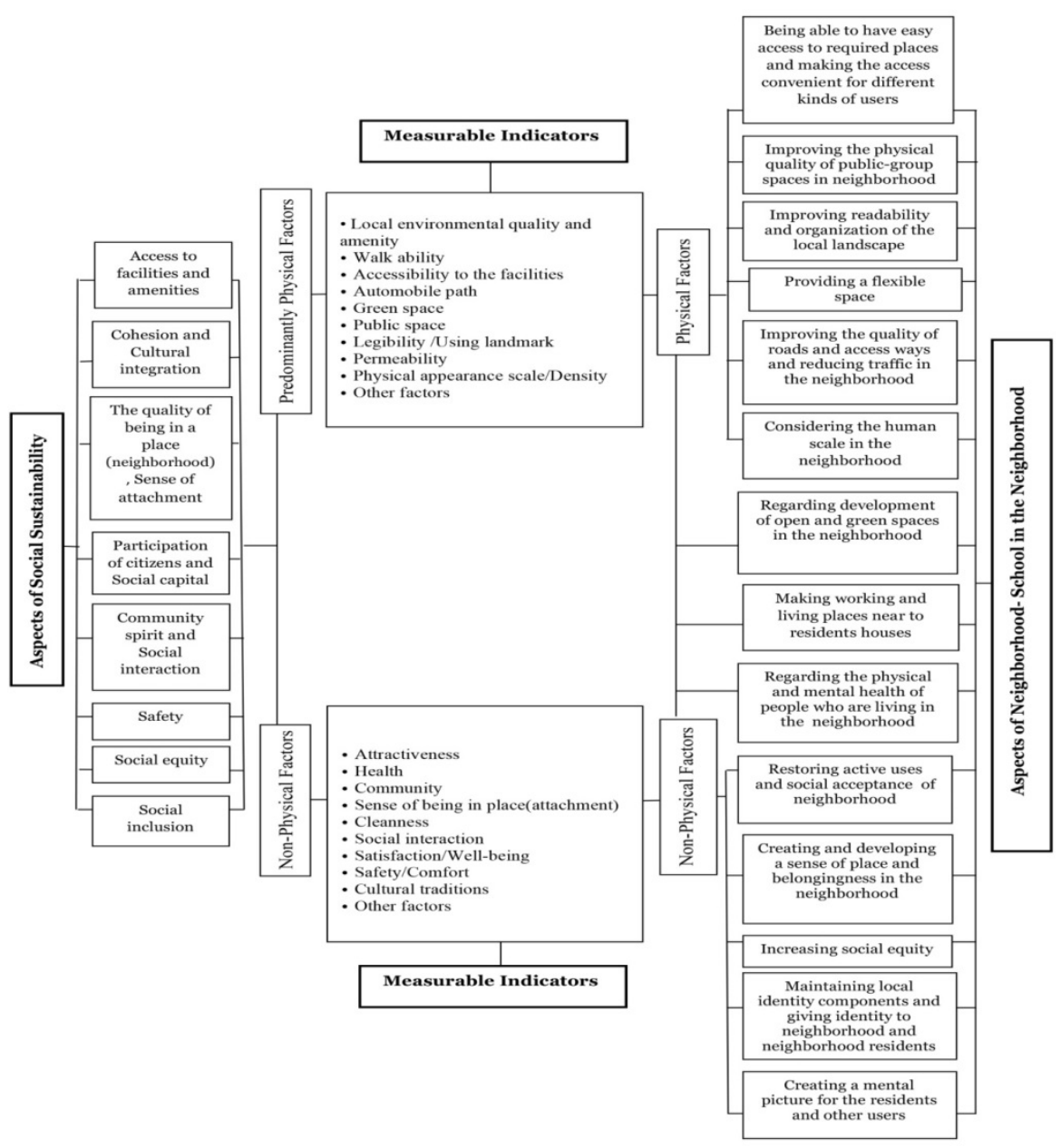

Figure 1. Analyzing the similarities and correspondence between social sustainability and aspects of neighborhood-school in the neighborhood (Source: Author, 2016) (cf. Dempsey et al., 2011)

A lot of principles and factors may be raised and analyzed for socially sustainable development in neighborhood scale, according to theories and experiences existing in social sustainability. The characteristics of the neighborhood were shaped by these social and physical design forces. The neighborhood is affected by these 
characteristics because of size, density, form, accessibility, legibility, and heterogeneity. These characteristics provide an environment that would heighten a feeling of belonging and contribute to a sense of community.

Accessibility to the neighborhood-school is in relation to the legibility in the neighborhood. Legibility is described as people's feelings of safety and sense of place through their orientation and way-finding (Kelly, 2001; Lynch, 1960). In this way, legibility is conceptually linked to the amount of accessibility to the neighborhood-school for residents and school users. Lack of attention to the location of the neighborhood-school can affect the roadways and crowding around the school which has a negative impact on noise intensity within the neighborhood and exacerbates the problem of noise pollution. Other research findings support these claim showing the strong relationship between orientation and the dimensions of satisfaction, social cohesion, and sustainable communities. Sustainable communities in a neighborhood incorporate a number of features of quality of the built environment and dimensions of social cohesion (Dempsey, 2009).

Creation of a harmonious living environment is related to the quality of building designs and surroundings. It contains compatibility with the neighborhood, the layout of streets and buildings. These elements should be designed to create a harmonious living environment and improve the quality of citizen's lives (Chan \& Lee, 2007). The appearance and scale of the buildings of the neighborhood facilities can be highlighted through promotion of local characteristics. The physical appearance of the neighborhood-school should be in relation to the neighborhood context.

Many researchers would argue that aesthetics are effective in achieving a good physical environment and social sustainability due to people responding to the aesthetics of their environment in terms of their sense of satisfaction (Chan \& Lee, 2007). Poor condition of the built environment is claimed to have a negative psychological effect on people's sense of safety (Bramely et al., 2009). Therefore, the different shapes, features, colors and contrasts, varying roof lines, a variety of front doors, and windows of the buildings create interesting and attractive places for residents.

In addition, perceptions of attractiveness can also be influenced by decoration and ornamentation, public art and architectural characteristics (Moughtin et al., 1999). Residents refer to characteristics of neighborhoods as well as to features of the built environment when describing and assessing the character of their neighborhoods (Dempsey, 2009). The research supports the inclusion of physical appearance and architectural features of the neighborhood-school at the neighborhood level. It provides evidence suggesting a link between quality of the built environment and these dimensions of perceived attractiveness, perceived safety, sense of community and sense of place attachment. Furthermore, the perceived quality of the neighborhood, the attractiveness of the built environment and the green space and open walkway, contributed significantly to the prediction of a sense of community and place attachment (Ibid; 335). Also, perceived neighborhood in terms of attractiveness can be in relation to higher density and height of neighborhood buildings (Karuppannan \& Sivam, 2011). Density of the buildings in the neighborhood can affect the appearance and aesthetics of the neighborhood and hence people's attachment to and pride in it (Bramely et al., 2009). The density also can affect the perceptions of crowding and social interaction of the residents within the neighborhood. It was also found that crowding within buildings reduces the possibility of social interaction and community spirit. The density is in relation to the perceptions of density, the built forms, and layouts. Therefore, designing buildings in a neighborhood has an important role in achieving social sustainability (Dave, 2011).

Chan and Lee (2007) argue that a neighborhood will be called sustainable if it creates a pleasant living environment, reduces social inequality and improves quality of life. Indeed, for designing and locating the school in the neighborhood, a lack of attention to the role of the school characteristics can provide additional traffic, reduced safety, poor walking opportunities and lack of harmony between the buildings around the school. It can make residents unsatisfied with their neighborhood conditions, and this is not sustainable.

Following the literature review stage, to measure the social sustainability as the outcome of present research seven indicators that assumed as depended variables, are listed below:

- Neighborhood as a place to live in

- Equal access to services and welfare benefits

- Opportunities for social interaction and community

- Health of the residents and cleanliness

- Sense of safety and comfort

- Image of neighborhood and quality of neighborhood (attractiveness) 
- Sense of attachment (being in place) and satisfaction (well-being) in neighborhood

Overall, the above items of neighborhood-school characteristics are arranged as the six important factors as in depended variables (physical and non-physical aspects of neighborhood-school) to indicate that certain design features should be incorporated for achieving social sustainability (Figure 2).

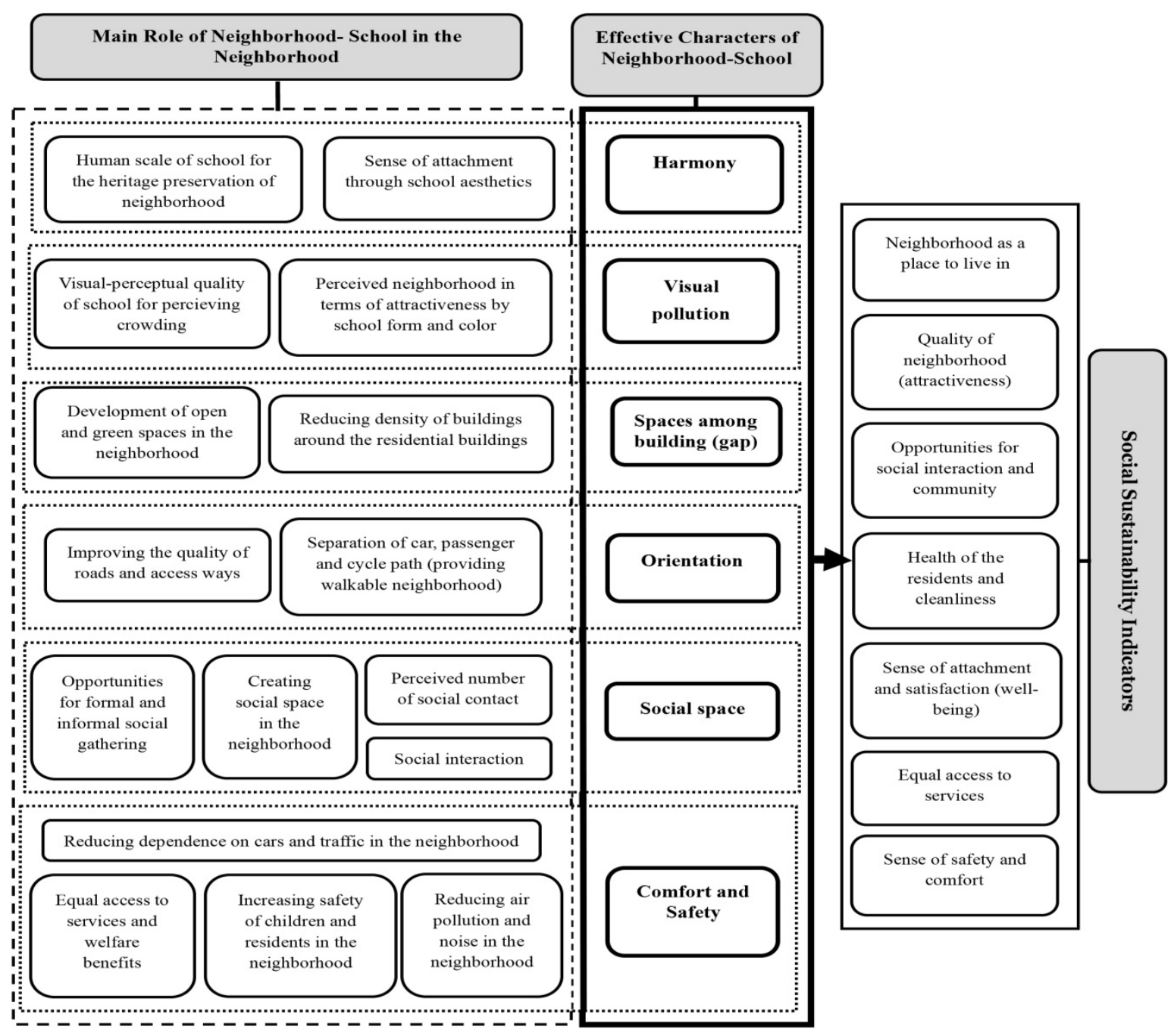

Figure 2. The theoretical framework of present research (Source: Author, 2016)

\section{Method}

Following the literature review, two case studies were required, to measure the relationship between quality of neighborhood-school (in primary school level) as the neighborhood facilities and social sustainability, to indicate the possibility of the range of factors having an effect on social sustainability. The identified characteristics and dimensions of the concepts were translated into sets of measurable indicators, which listed in Figure 2. It is important to note that characteristics of quality were examined in relation to opinions that measure social sustainability as reported by residents.

\subsection{Case Study}

In Iran, the neighborhood is defined as a framework of residence and employment of 700-1250 households (3500-6250 peoples) with pedestrian access radius fluctuation range of 4-5 min. In this definition, the neighborhood includes the main elements that are determinant in its formation. These elements form the neighborhood structure in two levels including indicator elements (such as primary school and mosque) and distributive elements (such as daily and weekly commercial centers, neighborhood parks, sport places and health centers) (Habibi \& Masaeli, 1999). In Kerman, unfortunately, there are not primary schools in each neighborhood. 
Therefore, two case studies were used -i.e., a neighborhood with neighborhood-school and non-neighborhood-school, rather than a single case study, because they enable a comparison to be made to understand the effect of neighborhood-school characteristics on the neighborhood. In order to capture the impact of neighborhood-school characteristics on social sustainability of neighborhood, the neighborhoods were selected to control case of non-neighborhood-school and case with neighborhood-school for measuring the effect more effectively. The studied areas, where the majority of buildings in the neighborhood are residential, are Hamzeh Blvd (with neighborhood-school) and Moallem Blvd (non-neighborhood-school), Kerman, Iran (see Figure 3). The selected neighborhoods are linked with Jomhouri Blvd (the main street) in the Kerman. Many other buildings were built along these neighborhoods and created a city center consisting of various urban activities and functions. Today, all these buildings are old and represent the past architectural patterns. Indeed, because of this background, these areas play a significant role in resident satisfaction and attachment due to the different kinds of facilities around these areas.

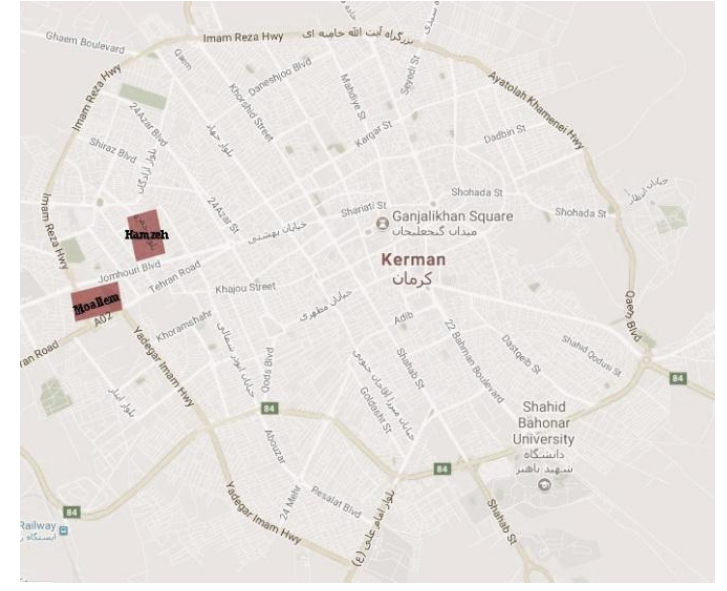

a

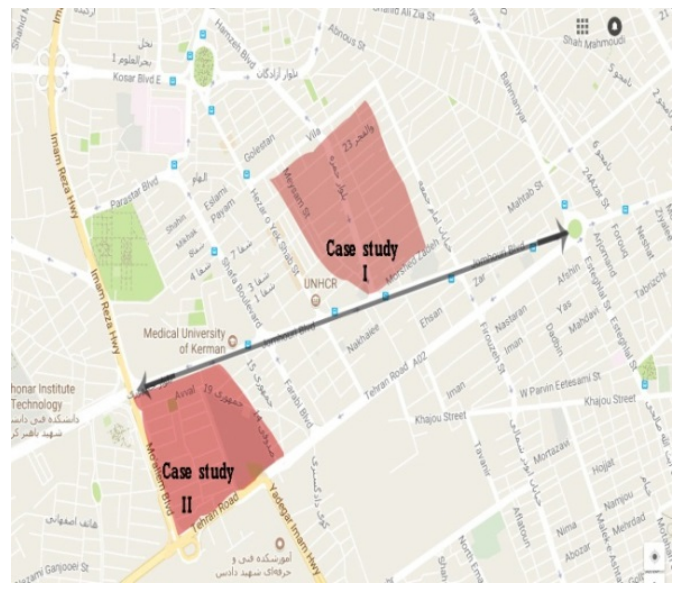

b

Figure 3. The location of Hamzeh Blvd and Moallem Blvd, Kerman, Iran; a) Kerman city and two case studies location, b) The location of two case studies and Jomhouri Blvd as the main street of Kerman (Source:

Author,2017)

\subsubsection{Neighborhood I-a Case with Neighborhood-School}

The main reason for considering this neighborhood as one of the case studies for this research is that it is one of the main areas with several schools in different levels -primary school, secondary school and high school- which are in the vicinity of the Jomhouri Blvd as the main street of Kerman (Figure 4). In terms of traffic, due to having several schools, this neighborhood is a semi-active neighborhood with no heavy traffic. Based on the spatial analysis of the Hamzeh neighborhood, the urban texture was formed around the main street of Hamzeh. This neighborhood was known as one of the liveliest urban spaces in the city.

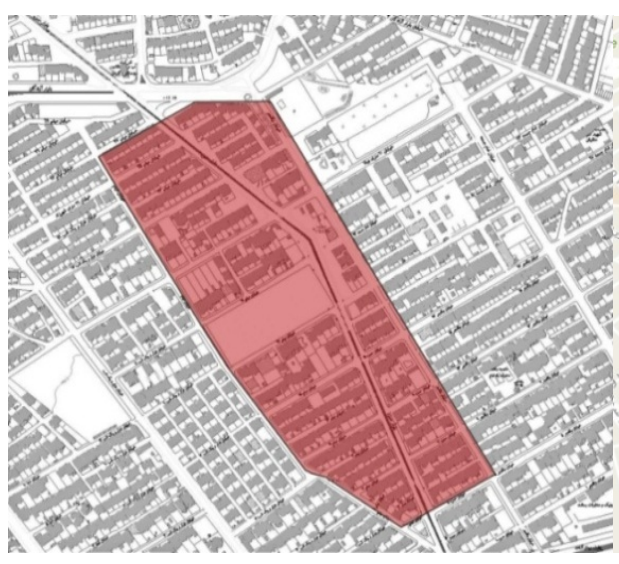

a

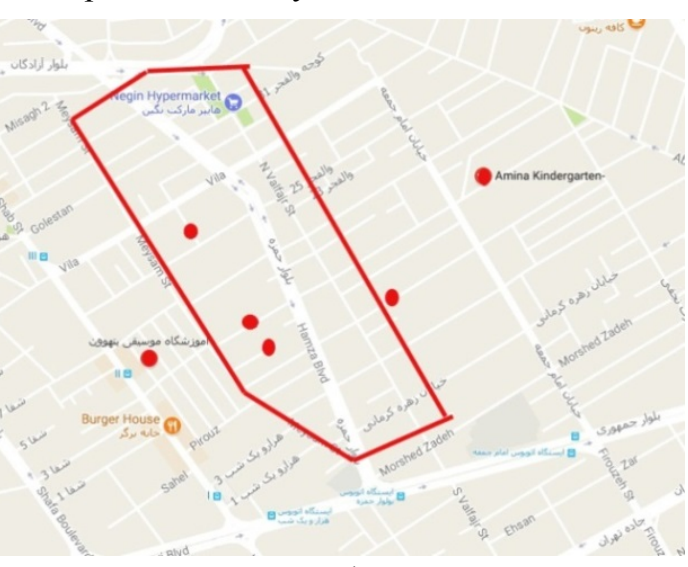

$\mathrm{b}$

Figure 4. The Hamzeh Blvd location, Kerman, Iran; a) Hamzeh Blvd boundary b) Location of Hamzeh schools

(Source: Author, 2014) 


\subsubsection{Neighborhood II-a Case of Non- Neighborhood-School}

Case study II is Moallem Blvd and also located in the south of Jomhouri Blvd as the main street of Kerman. It is bounded to the south by Tehran road that is another main boulevard of Kerman (Figure 5). There is no primary school for neighborhood children and residents. The nearest neighborhood that Moallem residents are forced to travel to school is Hamzeh neighborhood. Indeed, due to this background, this area has a significant role in reducing residents' satisfaction and attachment in Moallem neighborhood.

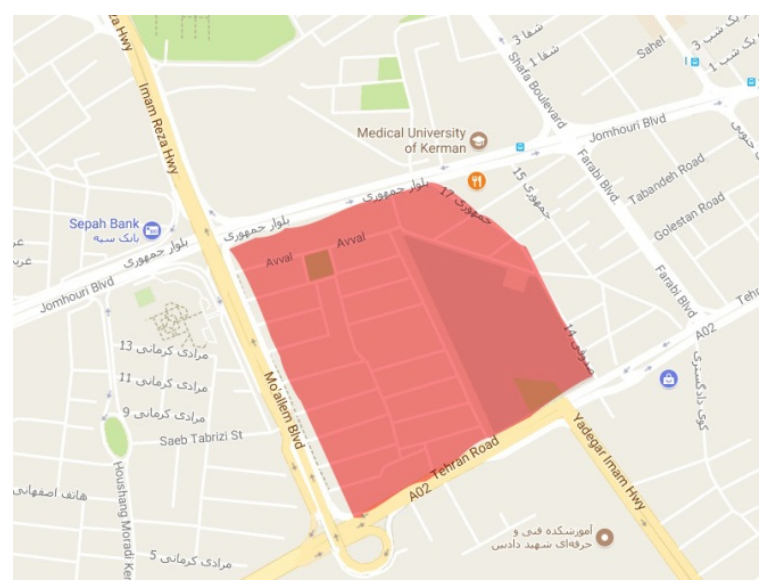

Figure 5. The location and boundary of Moallem Blvd, Kerman, Iran; (Source: Author, 2016)

\subsection{Participants}

People's participation can be encouraged to help in decision making and management, to help increase levels of involvement, and finally for funding purposes (Ricmanchian \& Rismanchian, 2007 cites Alavitabar, 2003).

The field study and statistical population consist of two groups; the first group contains local residents of neighborhood I (Hamzeh Blvd) of different genders in the age range of 25-50. The second group contains local residents of neighborhood II (Moallem Blvd) in the age range of 25-50 associated with the selected neighborhood. (Table 2).

Table 2. Frequency distribution of the participants' sample to the separate group

\begin{tabular}{cccccc} 
& Gender & Frequency & Percent & Valid Percent & $\begin{array}{c}\text { Cumulative } \\
\text { Percent }\end{array}$ \\
& & & & $56.9 \%$ \\
The First & Male & 66 & $55 \%$ & $56.9 \%$ & $100 \%$ \\
Experimental & Female & 50 & $41.7 \%$ & $43.1 \%$ & - \\
Group (first EG) & Total & 116 & $96.7 \%$ & $100 \%$ & - \\
& Missing & 4 & $3.3 \%$ & - & - \\
System & Total & 120 & $100 \%$ & - & $100 \%$ \\
The Second & Male & 54 & $45 \%$ & $47 \%$ & - \\
Experimental & Female & 61 & $50.8 \%$ & $53 \%$ & - \\
Group (second & Total & 115 & $95.8 \%$ & $100 \%$ & - \\
EG) & Missing & 5 & $4.2 \%$ & - & - \\
\hline System & Total & 120 & $100 \%$ & & - \\
\hline
\end{tabular}

(Source: Author, 2016) 
The population of neighborhood I and II in a 600 -meter accessible radius in the neighborhood, based on the definition of urbanism theorists about neighborhood, is approximately 1100 households. Therefore, to estimate the size of a sample, Cochran's formula was used. This is one of the statistical methods that is commonly associated with the study of qualitative variables that are used to determine sample size (Cochran, 1977).

$$
N=\frac{\frac{\mathrm{z}^{2}}{4 \mathrm{~d}^{2}}}{1+\frac{1}{\mathrm{~N}}\left(\frac{\mathrm{z}^{2}}{4 \mathrm{~d}^{2}}-1\right)}
$$

$Z=1.96$, value for selected alpha level; $d=0.05$, estimate of variance; $N=1100$, households of residents in 600 meters radius accessibility of both neighborhoods.

The main purpose of considering different groups of participants was to analyze diverse groups of neighborhood residents and diverse opinions among participants. An experiment was designed and 285 people of the neighborhoods participated based on the Cochran formula.

\subsection{Instruments}

To investigate the effect of neighborhood-school on social sustainability, questionnaires which included the categories of semi-closed and semi-open questions were used. A questionnaire technique was selected to obtain residents' opinions regarding the neighborhood characteristics because of its advantage in making it possible for an investigator to obtain in-depth information by probing (Karuppannan \& Sivam, 2011).

Various methods of participation were used in the research such as questionnaire, direct conversation. Analyzed groups consist of 285 people who were chosen randomly from both neighborhoods' residents (neighborhood I and II). The questionnaires were distributed among all participants with 45 not returned (Table 3 ).

Table3. Frequency distribution of the participants' sample to the separate group

\begin{tabular}{cccccc}
\hline & Groups & Frequency & Percent & $\begin{array}{c}\text { Valid } \\
\text { Percent }\end{array}$ & $\begin{array}{c}\text { Cumulative } \\
\text { Percent }\end{array}$ \\
\cline { 2 - 5 } The First & & 39 & $32.5 \%$ & $32.5 \%$ & $32.5 \%$ \\
Experimental & The residents of Hamzeh Blvd & 81 & $67.5 \%$ & $67.5 \%$ & $100 \%$ \\
Group (first & Potal & 120 & $93.3 \%$ & $100 \%$ & - \\
EG) & Parents & 31 & $25.8 \%$ & $30.7 \%$ & $30.7 \%$ \\
The Second & 70 & $58.3 \%$ & $69.3 \%$ & $100 \%$ \\
Experimental & The residents of Moallem Blvd & 101 & $84.2 \%$ & $100 \%$ & - \\
Group & Total & 19 & $15.8 \%$ & - & - \\
(second EG) & Missing System & 120 & $100 \%$ & - & - \\
& Total & & &
\end{tabular}

(Source: Author, 2016)

The two steps of the research are presented below:

First step: The first Experimental Group (first EG); neighborhood I residents are defined as the first group of this research. In this step has been tried to ask residents to fill out questionnaires about the role of neighborhood-school in the Hamzeh Blvd as the case with neighborhood-school.

Second step: The second Experimental Group (second EG); consisting of neighborhood II residents as the case of non-neighborhood-school, was presented with a questionnaire and asked about the six indicators of affective aspects of the school in the neighborhood (Table 4). 
Table 4. Indicators measuring of the first and second EG

\begin{tabular}{ccc}
\hline Indicators Measuring & \multicolumn{1}{c}{ Summary of Indicators } & Number of Items \\
\hline Harmony & $\begin{array}{c}\text { Considering the human scale, Neighborhood scale, Physical } \\
\text { appearance, Maintaining local identity of the neighborhood, } \\
\text { Compatibility with neighborhood }\end{array}$ & 7 items \\
Visual pollution & $\begin{array}{c}\text { Physical quality, Density in neighborhood, Building } \\
\text { boundary, Perceived crowding by buildings }\end{array}$ & 5 items \\
Spaces among building \\
(gap) & $\begin{array}{c}\text { Outside spaces, Development of open spaces, Cleanness } \\
\text { neighborhood through building skyline, Mental health } \\
\text { through building crowding }\end{array}$ & 4 items \\
Orientation & $\begin{array}{c}\text { Pedestrian and vehicles paths, Legibility-school as a } \\
\text { landmark in neighborhood, Organization of the local } \\
\text { landscape }\end{array}$ & 4 items \\
Social space & $\begin{array}{c}\text { Social contact between residents and students, Formal } \\
\text { and informal social interaction between residents } \\
\text { Easy access to the neighborhood, Perceived crowed } \\
\text { neighborhood by different school users, The number of } \\
\text { cars, Walkable neighborhood through locating a school }\end{array}$ & 4 items \\
& items \\
\hline
\end{tabular}

(Source: Author, 2016)

The questions in the questionnaires were answered to achieve the six factors of the quality of neighborhood-school (independent variable) on socially sustainable development in neighborhood (go to Figure 2). These six factors contained Harmony, Visual pollution, Spaces among building (gap), Orientation, Social space, Comfort and Safety. Questionnaires were filled by residents of neighborhood I and II. Some important questions were as follows:

\begin{tabular}{|c|c|c|}
\hline \multirow{6}{*}{ 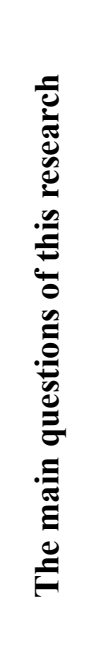 } & Harmony & $\begin{array}{l}\text { - The effect of school's building variety on providing grace and } \\
\text { attractiveness in the neighborhood. }\end{array}$ \\
\hline & $\begin{array}{c}\text { Visual } \\
\text { pollution }\end{array}$ & $\begin{array}{l}\text { - The effect of the school form and height on quality and general } \\
\text { appearance of the neighborhood. }\end{array}$ \\
\hline & $\begin{array}{l}\text { Spaces among } \\
\text { building(gap) }\end{array}$ & $\begin{array}{l}\text { - The effect of school location in relation to other neighborhood } \\
\text { buildings on quality of neighborhood and residents' satisfaction } \\
\text { (measuring crowding of the building). }\end{array}$ \\
\hline & Orientation & $\begin{array}{l}\text { - How much do we need to build a school in the neighborhood for } \\
\text { decreasing distance and making a situation for walking to school because } \\
\text { of making calmness for resident of the neighborhood? }\end{array}$ \\
\hline & Social space & $\begin{array}{l}\text { - The effect of the neighborhood- school for promoting cultural and } \\
\text { social issues in neighborhood. }\end{array}$ \\
\hline & $\begin{array}{l}\text { Comfort and } \\
\text { Safety }\end{array}$ & $\begin{array}{l}\text { - The importance of the school path for making connections between } \\
\text { school and neighbors' buildings on calmness and comfort. }\end{array}$ \\
\hline \multirow{4}{*}{ 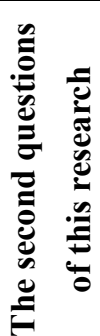 } & \multicolumn{2}{|c|}{$\begin{array}{l}\text {-The importance of locating the school in the neighborhood to encourage communication } \\
\text { between children and their parents and local residents. }\end{array}$} \\
\hline & \multicolumn{2}{|c|}{$\begin{array}{l}\text { - How important is it for the school to be connected with other spaces such as local public } \\
\text { spaces, etc (for use of services in the neighborhood)? }\end{array}$} \\
\hline & \multicolumn{2}{|c|}{ - The effect of vitality and community by school in the neighborhood. } \\
\hline & \multicolumn{2}{|r|}{ fect of neighborhood-school on the welfare of the neighborhood. } \\
\hline
\end{tabular}

Note. All respondents rated the extent to which individual neighborhood-school characteristics affected quality of the neighborhood according to a 5-point Likert scale (" 1 " =too much, " 2 " " =much, " 3 " = partly, " 4 " = low, " 5 " =very low). 


\section{Findings and Discussion}

As mentioned in sustainable development, using some facilities such as shops, a primary school, health facilities, open spaces and parks in the neighborhood can provide sustainability. When these facilities are located in the neighborhood they provide some activities and environmental, social, cultural, and economic benefits. These benefits affect quality of the neighborhood and the residents' lives.

In this part of the paper, the results of the data analysis are presented. Data collection was done by using a questionnaire including; a 28-item close-ended item questionnaire (Note 1). Data were analyzed through descriptive and inferential statistics and EXCELL2010 as well as Statistical Package for Social Science (SPSS16). Besides, inferential statistics were used to examine the research questions by using one-sample t-test, Friedman, and independent t-test.

A preliminary series of Principal Component Analyses (PCAs 1) was run on each of the six factors to establish the more reliable physical and social factors between school and neighborhood. The following 28 factors were found to investigate the research question. One sample t-test was used. A 5-scale range was considered and the basic mean was 3 . Regarding the significance level of this test ( $\mathrm{p}=0.0000<\alpha=0.01$ ), (Table 5), (Figure 1).

Table 5. One sample t-test for comparing the sample and basic mean in the neighborhood-school factors; First EG

\begin{tabular}{cccccc}
\hline & \multicolumn{5}{c}{ Test Value $=3$} \\
\hline Mean Harmony & $\mathrm{N}$ & $\mathrm{T}$ & $\mathrm{df}$ & P-Value & Mean Difference \\
3.74 & 120 & 12.15 & 119 & 0.000 & 0.74 \\
Mean Visual pollution & $\mathrm{N}$ & $\mathrm{T}$ & $\mathrm{df}$ & P-Value & Mean Difference \\
4.20 & 120 & 26.45 & 119 & 0.000 & 1.20 \\
Mean Spaces among & $\mathrm{N}$ & $\mathrm{T}$ & $\mathrm{df}$ & P-Value & Mean Difference \\
building(gap) & 120 & 20.08 & 119 & 0.000 & 1.20 \\
4.20 & $\mathrm{~N}$ & $\mathrm{~T}$ & $\mathrm{df}$ & P-Value & Mean Difference \\
Mean Orientation & 120 & 22.42 & 119 & 0.000 & 1.02 \\
4.02 & $\mathrm{~N}$ & $\mathrm{~T}$ & $\mathrm{df}$ & P-Value & Mean Difference \\
Mean Social space & 120 & 20.29 & 119 & 0.000 & 1.08 \\
4.08 & $\mathrm{~N}$ & $\mathrm{~T}$ & $\mathrm{df}$ & P-Value & Mean Difference \\
Mean Comfort and Safety & 120 & 24.60 & 119 & 0.000 & 1.35 \\
4.35 & & & &
\end{tabular}

(Source: Author, 2016)

For the first EG, the Friedman test was used to examine the highest and lowest levels of the six factors according to the residents' opinions; its result is presented in Figure 2, Regarding the significant level of this test $(\mathrm{p}=0.0000<\alpha=0.01),\left(\chi^{2}=103.02, \mathrm{df}=2, \mathrm{p}<0.01\right)$, with $99 \%$ confidence, it can be said that according to the residents of the neighborhood I in this study, the importance of the various indices which affect the environment of the neighborhood was different. So, among the six factors, the highest level belongs to the comfort and safety factor (mean rank $=4.35$ ) and the lowest level belongs to the harmony factor (mean rank $=3.74$ ). Therefore, residents believe that the comfort and safety factor is the most important in comparison with other neighborhood-school characteristics. 


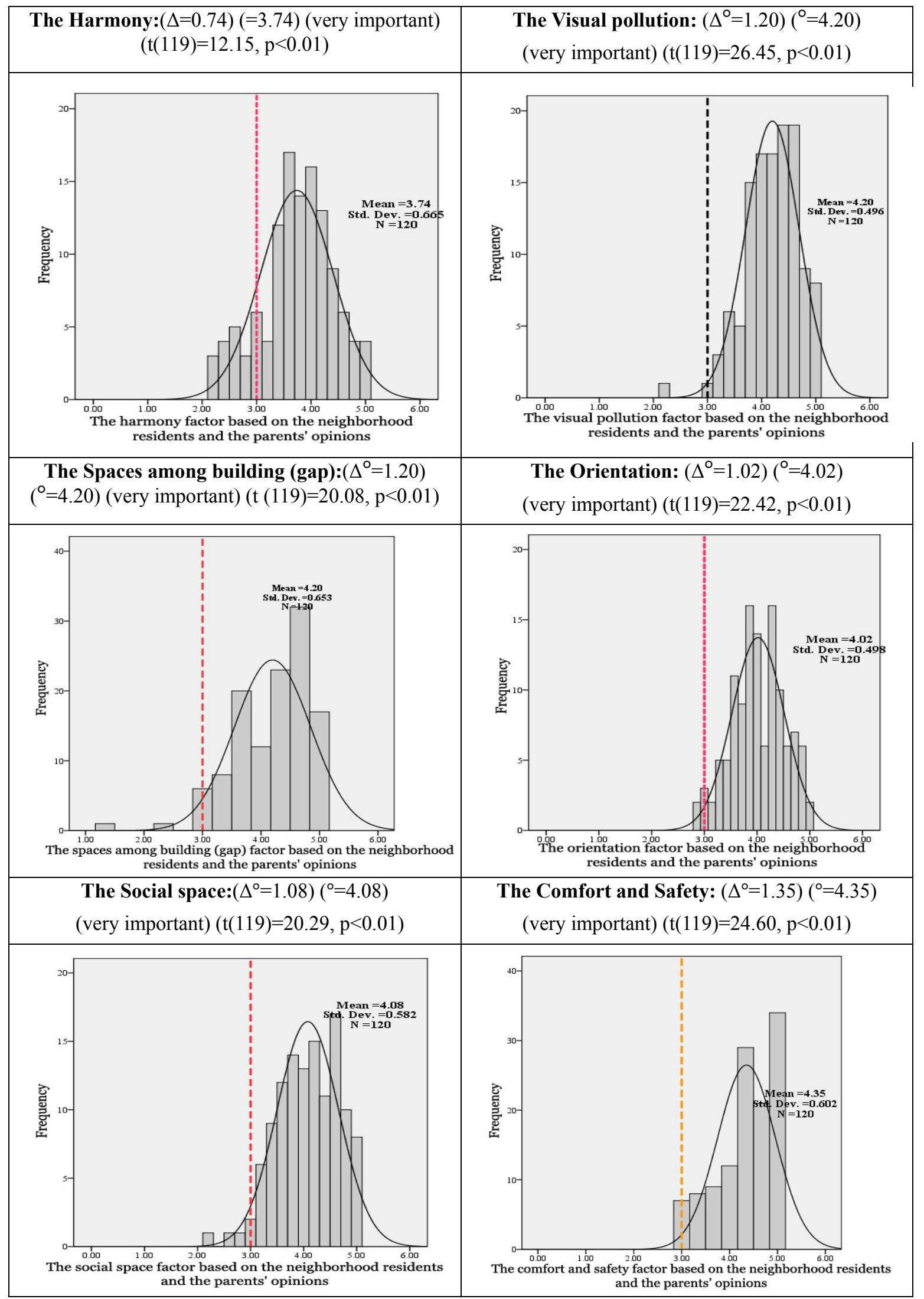

Figure 1. Histogram of neighborhood-school factors based on the neighborhood residents' opinions

(Source: Author, 2016) 
A secondary series of Principal Component Analyses (PCAs 2) was run on each of the six scales to demonstrate the effect of neighborhood-school on the social sustainability of the neighborhood (Table 6). According to the second EG; of the six indicators of neighborhood-school features which can affect the neighborhood, the Moallem Blvd residents' opinions indicated the highest mean belongs to harmony and physical appearance $(\mathrm{SD}=1.74, \mathrm{M}=6.07)$. The participants (second $\mathrm{EG}$ ) prefer their neighborhood with varied architectural features and more interesting than those with repetitive form and features (Figure 2) (Note 2).

Table 6. The overall effect of the neighborhood-school characteristics; second EG

\begin{tabular}{|c|c|c|c|}
\hline List of & Number of & Overall Effect on Quality of the N & borhood \\
\hline \multirow[b]{2}{*}{ Harmony } & \multirow[b]{2}{*}{$\begin{array}{l}\text { Seven } \\
\text { features }\end{array}$} & Perceived Positive & Perceived Negative \\
\hline & & $\begin{array}{l}\text { - The visual effect of the school } \\
\text { - The harmony of the school characteristics with } \\
\text { the surrounding environment }\end{array}$ & $\begin{array}{l}\text { - Designing school based } \\
\text { on the scale of } \\
\text { neighboring buildings }\end{array}$ \\
\hline $\begin{array}{l}\text { Spaces } \\
\text { among } \\
\text { building(gap) }\end{array}$ & $\begin{array}{l}\text { Five } \\
\text { features }\end{array}$ & $\begin{array}{l}\text { - The need for open and green spaces (gap) } \\
\text { around the school }\end{array}$ & $\begin{array}{l}\text { The relationship } \\
\text { between outside and inside } \\
\text { of the school with } \\
\text { neighborhood }\end{array}$ \\
\hline Social spaces & $\begin{array}{l}\text { Four } \\
\text { features }\end{array}$ & $\begin{array}{l}\text { - The collective places out of the school } \\
\text { environment for neighbors who live near the } \\
\text { school }\end{array}$ & - \\
\hline Orientation & $\begin{array}{l}\text { Four } \\
\text { features }\end{array}$ & $\begin{array}{l}\text { - The effect of the school outside paths on the } \\
\text { neighborhood paths } \\
\text { - Visible signs for legibility to the school in the } \\
\text { neighborhood } \\
\text { - Providing walkability in the neighborhood }\end{array}$ & $\begin{array}{l}\text { - The school provide } \\
\text { vehicles with limitation of } \\
\text { accessing to the } \\
\text { neighborhood }\end{array}$ \\
\hline $\begin{array}{l}\text { Visual } \\
\text { pollution }\end{array}$ & $\begin{array}{l}\text { Four } \\
\text { features }\end{array}$ & $\begin{array}{l}\text { - The green space of school in the vicinity of } \\
\text { neighborhood effect on visual crowding }\end{array}$ & $\begin{array}{l}\text { - Perceived privacy within } \\
\text { the neighborhood }\end{array}$ \\
\hline $\begin{array}{l}\text { Comfort and } \\
\text { Safety }\end{array}$ & Four features & $\begin{array}{l}\text { - Pollution and traffic within the neighborhood } \\
\text { - Provide comfort through easy access to school }\end{array}$ & $\begin{array}{l}\text { - Environment cleanliness } \\
\text { - Perceived problem of } \\
\text { school noise }\end{array}$ \\
\hline
\end{tabular}

(Source: Author, 2016)

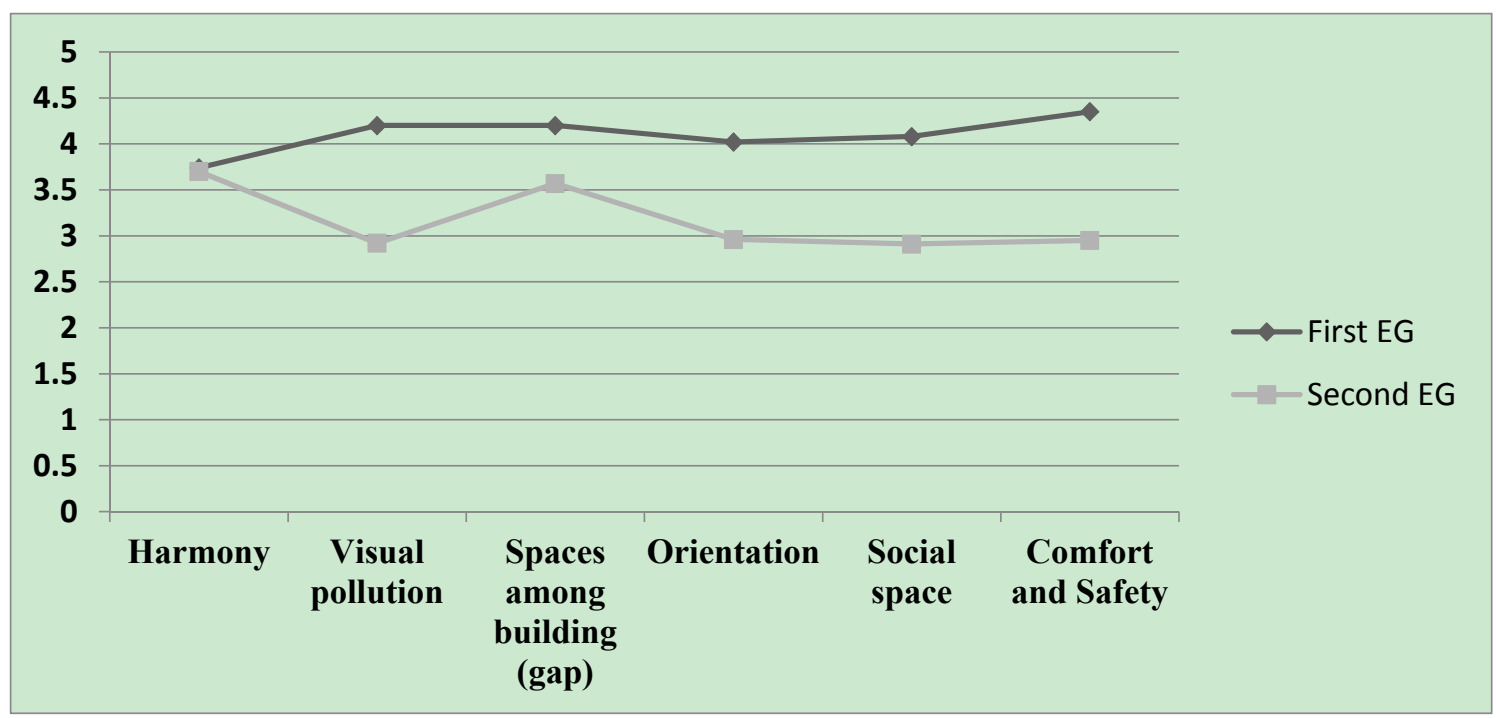

Figure 2. The ranking of the factors based on the First and Second EG (Source: Author, 2016-2017) 
The findings of the interview (Note 3), involving a qualitative questionnaire, revealed that most of the residents (second EG) complain about the lack of neighborhood-school in the vicinity. It has forced children to go far away to school by car. They claimed that if the school were in the vicinity of their neighborhood it would be easy for children to go to school with their friends. It may have positive consequences such as walking, communicating, bike riding, and physical activities which cause mental and physical well-being. Strong points of the neighborhood from the interviewees' points of view (first EG) are the existence of a school in the neighborhood would provide close relationships between residents (i.e., interaction). In continue, according to neighborhood-school characteristics in Figure 2, these factors are analyzed briefly.

\section{Factor I- Harmony:}

Clarity in the perception of neighborhood and easy familiarity and integration between its elements, other buildings and neighborhood facilities may be deemed as neighborhood identity. Perception of unity and proportion of the neighborhood buildings impacts on the attachment and attractiveness. The scale and attractive neighborhood-school buildings reduce the negative impacts on its surroundings. Most participants (both first and second EG) believed that the neighborhood-school building could provide the pleasant physical appearance to see their own neighborhood attractive, beautiful and colorful. Participants (second EG) also agreed with different shapes of the school building. It means that it is assumed as the important and first factor in neighborhood identity for residents. Due to the absence of harmony and highest diversity of buildings' appearance in neighborhood II, by its frequent facilities, residents were interested in having neighborhood-school to provide variety in its context.

\section{Factor II- Visual pollution:}

One of the subjects that is directly connected to density and has direct effects on quality of life in neighborhood scale is tolerable capacity. Neighborhood's tolerable capacity evaluation factors may be classified and provided in three groups; physical development capacity of neighborhood, neighborhood access capacity, and natural characteristics of the neighborhood. Neighborhood capacity is another factor of visual pollution that impacts on residents' health and well-being. Locating the neighborhood-school in out of the neighborhood capacity range and neighborhood density causes destruction of resources capacity and natural characteristics of the neighborhood. The participants preferred to pay attention to the density of neighborhood-school buildings and their height to reduce visual pollution and to maintain cleanliness. Based on the participants' opinions (second EG) the neighborhood buildings were too tall compared to the width of streets. So, the neighborhood-school building with good composition of mass and space can make balance and improve the current problem.

Factor III- Spaces among building (gap):

Due to the different function of neighborhood-school and other neighborhood facilities from other residential buildings in the neighborhood, it is obvious the neighborhood facilities need a boundary to separate different functions. Enough space between buildings organizes the neighborhood shape. Participants' opinions demonstrated that the open and green spaces around the neighborhood-school would not only play the role of a center for the neighborhood but also good open space would enhance social interaction and help in promoting both health, and social inclusion and aesthetics. This factor directly is in relation to residents' satisfaction. They also believed that open spaces and built-up areas would be well-balanced through green spaces around the neighborhood-school.

\section{Factor IV-Orientation:}

Design streets as a public space and enhancement of bicycle use within and outside the neighborhood, through well-connected districts, develop contiguous compact neighborhoods around nodes of varying sizes and avoid urban sprawl. Due to the current situation in neighborhood II, the residents use the automobile for school and their daily needs. So, there is not enough space to walk and it is dangerous to cycle. The participants (second EG) predicted that their neighborhood would be well-suited for walking and cycling, well-connected with main streets of the city and it would be easy to go out from this neighborhood by suitable location of neighborhood-school and its paths. Some other participants (first EG) thought in this case, due to increasing the population through locating a primary school, main streets of the neighborhood were likely to have a high traffic volume in some day hours.

Factor V-Social space:

In order to craft sustainable neighborhoods, the fulfillment of basic physical needs, social relationship as well as safety and security is necessary. The existence of neighborhood-school lets residents to do not go out of neighborhood and it causes attachment and social engagement to their neighborhood. In addition, 
neighborhood-school effects social interaction between children and parents through decreasing the mobility and increasing the contact of residents in each neighborhood. The fact in neighborhood I is children and teenagers are forced to move from other neighborhood to this neighborhood to go to school. Thus, participants (first EG) perceived their neighborhood as crowded with people who came to neighborhood for its facilities and schools. Crowding has a negative impact on social contact. The participants believed that they could not know all the people in neighborhood, involved in various community activities at various level (formal and informal), and perceived friendliness of the neighborhood.

\section{Factor VI- Comfort and Safety:}

The comfort and security are the serious problems and concerns in residential neighborhoods. Determination of traffic accident is assumed as the security factor. The traffic of neighborhood and pedestrians cross are major problem of the neighborhood. People are more likely to interact with the neighborhood and lead to more participation in collective activities in safe place. The participants (first EG) recommended the neighborhood-school caused noise and bother for residents. They also thought neighborhood-school provided the extra traffic and crowded neighborhood. In this result, they believed the unsafe neighborhood was their main problem. Participants (first and second EG) agreed with comfort due to locating the school in neighborhood.

The findings suggest that access to the services for each neighborhood residents can provide opportunities for collective activities. The residents do not need to travel out of neighborhood for their daily needs. It causes that social engagement between residents because of frequent contact with neighborhood services and facilities. All the residents of both neighborhoods were satisfied with good- quality of the neighborhood. The attractiveness of the neighborhood buildings- e.g. neighborhood services and facilities- is one of the features of quality of the neighborhood.

Primary data collected also show that, in addition, elements such as social interaction levels, perceived neighborhood in terms of attractiveness, general appearance, road traffic and the nature of services and facilities may also have a bearing on residents' perceptions of quality. The findings also emphasize the entrance of the school, by showing its self, distinctively and legibly can effect on neighborhood grace. Other research questions such claims, arguing that density of school building and the boundary around the school-e.g., open spaces or green spaces- can lead to increase organization and decrease crowd of the neighborhood, as well as a reduction in non-sense of community, poor social networks and feelings of safety. The social benefits of attractive environment are associated with a sense of community, feeling of safety and sense of attachment. The analysis also indicates that as the extent of services and facilities in a neighborhood increases, so does perception of comfort. This is further reflected in the significant associations between neighborhood-school variables and dimensions of social sustainability.

The study also demonstrates that there is a strong relationship between school characteristics (as a facility) and residents' satisfaction as the main aim of social sustainability. Harmony, visual pollution, and spaces between building (gap) are important factors in creating a pattern between the school environment and neighborhood buildings. These three factors provide a sense of attachment, variety, and a sense of reducing crowd and density in the neighborhood. Also, the relationship between density and form of the neighborhood-school can result in an attractive place for children, especially for primary students.

In addition, these three factors not only have an effect on the aesthetics in the neighborhood with the physical environment and social factors but they can also affect perceived social sustainability since people respond to their environment in terms of their satisfaction. Attention to these factors might improve people's satisfaction. Orientation, social space, comfort, safety and walking access lead to decreased traffic in the neighborhood, and increase a sense of social interaction and social equity, and better management for streets in the neighborhood. So, these factors again affect the neighborhood residents' satisfaction.

The comfort, safety, and physical appearance of the neighborhood-school play a major role in providing people with various opportunities to develop safety, security, and aesthetics in the neighborhood, which lead to social sustainability of the neighborhood.

\section{Conclusion}

This paper has discussed which characteristics of the neighborhood-school are more effective in social and physical issues, to address all residents' satisfaction with being in the neighborhood. We argued that existence of primary school in each neighborhood might be a potential between the children and residents, and their engagement within neighborhood environment through their frequent attendance in neighborhood. In addition, when women have children, they become (at least temporarily) more tied physically to a local neighborhood - in 
terms of activities - often not working and so spending more time around home and the surroundings. And as the children get older and go to school, parents may engage in more social interaction through the kids at school and other school friends and parents. So, in this regard, children are a well-known phenomenon for social engagement. On the other hand, neighborhood-school and other neighborhood facilities can satisfy residents by decreasing the distance of residents' mobility from their own neighborhood to another neighborhood.

Due to the importance of locating neighborhood facilities in social sustainability as a capital for social issue, there is an interesting premise about the nexus between neighborhood-school and social sustainability. The school characteristics and school users' activities affect quality of neighborhood (by perceived crowding and noise, walkability through locating school, school building's appearance and height, etc) residents' attachment to the neighborhood, and residents' satisfaction. Data analysis demonstrate residential satisfaction has been defined as the experience of pleasure or gratification deriving from living in a specific place where there are neighborhood facilities and amenities especially primary school by good-quality characteristics in presented physical and social factors.

Therefore, any neighborhood-school design needs to consider and address the factors of school characteristics as indicated in this paper. Future research might explore practical design solutions using a sustainable design paradigm to improve the social sustainability of neighborhoods.

\section{References}

Barton, H. (2000). Conflicting perceptions of neighbourhood. In Barton H (Eds.), Sustainable Communities: The Potential for Eco-Neighbourhoods (pp. 3-18). Earth scan: London.

Barton, H., Davis, G., \& Guise, R. (1995). Sustainable Settlements: a Guide for Planners, Designers and Developers. University of the West of England and the Local Government Management Board: Bristol.

Barton, H., Grant, M., \& Guise, R. (2003). Shaping Neighbourhoods: a Guide for Health, Sustainability and Vitality. Spon: London.

Bramley, G., \& Power, S. (2009). Urban form and social sustainability: the role of density and housing type. Environment and Planning B36, 30-48. https://doi.org/10.1068/b33129

Bramley, G., Dempsey, N., Power, S., Brown, C., \& Watkins, D. (2009). Social sustainability and urban form: evidence from British cities. Environment and Planning A,41(9), 2125-2142. https://doi.org/10.1068/a4184

Burton, E. (2000). The compact city: just or just compact? A preliminary analysis. Urban Studies, 37(11), 19692001. https://doi.org/10.1080/00420980050162184

Burton, E. (2003). Housing for an Urban Renaissance: Implications for Social Equity. Housing Studies, 18(4), 537-562. https://doi.org/10.1080/02673030304249

Chan. E., \& Lee, G. K. L. (2007). Critical factors for improving social sustainability of urban renewal projects. Soc Indic Res, 85, 243-256. https://doi.org/10.1007/s11205-007-9089-3

Cochran, W. G. (1977). Sampling techniques (3rd Ed.). New York: John Wiley and Sons.

Coleman, J. S. (1988). Social capital in the creation of human capital. American Journal of Sociology, 94, s95-s120. https://doi.org/10.1086/228943

Dave, S. (2011). Neighbourhood Density and Social Sustainability in Cities of Developing Countries. Sustainable Development, 19, 189-205. https://doi.org/10.1002/sd.433

Dempsey, N. (2008). Does quality of the built environment affect social cohesion?. Urban Design and Planning, 161, 105-114. https://doi.org/10.1680/udap.2008.161.3.105

Dempsey, N. (2009). Are good- quality environments socially cohesion? Town Planning Review, 80(3), 316-345. https://doi.org/10.3828/tpr.80.3.5

Dempsey, N., Bramly, G., Power, S., \& Brown, C. (2011). The social dimension of social development: Defining urban social sustainability. Sustainable Development, 19, 289-300. https://doi.org/10.1002/sd.417

Forrest, R., \& Kearns, A. (2001). Social Cohesion, Social capital and the Neighbourhood. Urban Studies, 19 , 2115-2143. https://doi.org/10.1080/00420980120087081

Habibi, S. M., \& Masaeli, S. (1999). Urban land use standards. Tehran: International land \& settlement organization, p.13.

Harnik, P. (2003). The excellent city park system: what makes it great and how to get there. Washington, DC: The Trust for Public Land. 
Karuppannan, S., \& Sivam, A. (2011). Social sustainability and neighbourhood design: an investigation of $\begin{array}{lllll}\text { residents' satisfaction in Delhi. Local Environment, } & 16(9), & \text { 849-870. }\end{array}$ https://doi.org/10.1080/13549839.2011.607159

Kelly, A. (2001). Building Legible Cities, Bristol, Bristol Cultural Development Partnership.

Lawhon, L. L. (2009). The neighbourhood unit: physical design or physical determinism? Journal of Planning History, 8(2), 111-132. https://doi.org/10.1177/1538513208327072

Littig, B., \& Griessler, E. (2005). Social sustainability: a catchword between political pragmatism and social $\begin{array}{llll}\text { theory. International Journal of Sustainable Development, } & \text { 8, }\end{array}$ https://doi.org/10.1504/IJSD.2005.007375

Lynch, K. (1960). The image of the city. Cambridge, M A: MIT Press.

Masnavi, M. R. (2007). Measuring Urban Sustainability: Developing a Conceptual Framework for Bridging the Gap Between Theoretical Levels and the Operational Level. Int.J. Environ.Res, 1(2),188-197.

McLaren, V. W. (1996). Urban Sustainability reporting. J.Am. Plan.Associat., 62(2), 184-203. https://doi.org/10.1080/01944369608975684

Mitchell, L., \& Elizabeth, B. (2006). Neighbourhood for life: Designing dementia-friendly outdoor environments, Quality in Ageing - policy. practice and research, 7, 26-33. https://doi.org/10.1108/14717794200600005

Morris D., \& Hess K. (1975). Neighbourhood Power: The New Localism. Boston, MA: Beacon Press.

Moughtin, C., OC, T., \& Tiesdell, S. (1999). Urban Design: Ornament and Decoration. Oxford, Architectural Press.

Partridge, E. (2005). Sustainability: a useful theoretical framework, Paper presented at The Australasian Political Science Association Annual Conference, 27-30 November, Dunedin, New Zealand.

Perry, C. (1927). The Neighborhood unit formula reprinted in wiliam L.C wheat on etaleds. Urban housing, New York, 94-109.

Pincetl, S. (2003). Nonprofits and park provision in Los Angeles: an exploration of the rise of governance approaches to the provision of local services. Social Science Quarterly, 84(4), 979-1001. https://doi.org/10.1046/j.0038-4941.2003.08404019.x

Putnam, R. D. (2000). Bowling Alone. Simon and Schuster. New York. https://doi.org/10.1145/358916.361990

Rismanchian, O., \& Rismanchian, A. (2007). Children participation in planning processes: the case of Child Friendly City project in post-earthquake Bam, Iran. URBAN DESIGN International, 12, 143-154. https://doi.org/10.1057/palgrave.udi.9000196

Rogerf, D. (1999). Toward an urban renascence. London, p. 67.

Stein, C. S. (1928). The Rad burn plan. Notes on the new town planned for the City Housing Corporation. In Parsons, K. C. (Ed.), The writings of Clarence S. Stein: architect of the planned community (John Hopkins University Press, Baltimore) 1998, 150-2.

Suminski, R. R., Petosa, R. L., \& Stevens, E. (2006). A method for observing physical activity on residential sidewalks and streets. Journal of Urban Health: Bulletin of the New York Academy of Medicine, 83(3), 434-443. https://doi.org/10.1007/s11524-005-9017-2

Teriman., Suharto., yigitcanlar., tan., mayere., \& severine. (2010). Sustainable urban development: formulation of indicator - based residential sustainability assessment framework for local level. In the $3^{\text {rd }}$ knowledge cities world summit, World Capital Institute, Melbourne Convention and Exhibition Centre, Melbourne, 604-613. https://doi.org/10.4018/978-1-61692-022-7.ch001

Trraga, O., \& Ngel, M. (2006). A Conceptual Framework to Assess Sustainability in Urban Ecological Systems, Int. J. Sustain. Develop. World Eco.

Wheeler, S. M. (2004). Planning for Sustainability. London: Routledge, p.199. https://doi.org/10.4324/9780203300565

Worpole, K. (2003). The social dynamic. In Neal P. (Eds.), Urban Villages and the Making of Communities (pp. 118-131). Spon: London. 


\section{Notes}

Note 1 . There were also some open-ended questionnaires regarding other effective factors that were answered by volunteers' participants of both case studies.

Note 2. Majority of participants (second EG) interested in living in a neighborhood with even located kindergarten due to its painted walls and, green and open spaces.

Note 3. The interview was done with both neighborhoods' participants during filling the questionnaire.

\section{Copyrights}

Copyright for this article is retained by the author(s), with first publication rights granted to the journal.

This is an open-access article distributed under the terms and conditions of the Creative Commons Attribution license (http://creativecommons.org/licenses/by/4.0/). 